\title{
Surgical stress detection in human blood plasma by DSC
}

\author{
Andrea Ferencz ${ }^{1}$. Dénes Lőrinczy ${ }^{2}$ \\ Received: 1 August 2019 / Accepted: 5 March 2020 / Published online: 17 March 2020 \\ (c) The Author(s) 2020
}

\begin{abstract}
It is a well-known fact that the extension of the surgical intervention influences both the success and time of the patient's recovery, the degree of the blood loss, i.e., overall the patients' surgical burden. Disease itself determines extent of surgical procedure (minor, intermediate or major surgery), which affects the risk and frequency of complications. Previous works have contributed to the validation of differential scanning calorimetry (DSC) as a potential non-invasive tool for diagnosing and monitoring several illnesses. Hence, the main goal of this study was to measure the effect of each surgical intervention on its own to blood plasma composition. Peripheral venous blood samples were collected from patients who underwent minor $(n=8)$, intermediate $(n=9)$ and major surgical interventions $(n=7)$. According our DSC data of blood plasma components, from the thermodynamic parameters, namely from the thermal transitions $\left(T_{\mathrm{m} 1}-T_{\mathrm{m} 8}\right)$ to calorimetric enthalpy $\left(\Delta H_{\text {cal }}\right)$ in proportion corresponded to the size of surgical interventions (duration of operation time, length of incision, surgical intraoperative stress, blood loss, etc.). This examination has shown that intraoperative stress during any surgical intervention affects the composition of plasma proteins, which should be always considered in the evaluation of DSC results in any surgical study.
\end{abstract}

Keywords Intraoperative stress $\cdot$ Minor surgery $\cdot$ Intermediate surgery $\cdot$ Major surgery $\cdot$ DSC $\cdot$ Blood plasma

\section{Introduction}

Risk of operation depends on the extent of the surgical intervention, the burden of anesthesia and the comorbidities. Definition of surgical stress, namely an operative intervention is major, or minor have been arisen for the first time in 1917 during a correspondence between Dr. Robert Earl and his patient, Mr. Lewis S. Pilcher, which is published in the American scientific literature [1]. The question was as follows: "Define what is meant by minor surgery and what is meant by major surgery?" The answer is still in place today, and it is invariably true: accordingly "I would say that major surgery includes all work requiring a general anesthetic; all operations which involve openings into the great cavities of

Andrea Ferencz

andrea.ferencz@gmail.com

Dénes Lőrinczy

denes.lorinczy@pte.hu

1 Department of Surgical Research and Techniques, Faculty of Medicine, Semmelweis University, Nagyvárad Sqr. 4, Budapest 1089, Hungary

2 Institute of Biophysics, Medical School, University of Pécs, Szigeti Str. 12, Pecs 7624, Hungary the body; all operations in the course of which hazards of severe hemorrhage are possible; all conditions in which the life of the patient is at stake; all conditions which require for their relief manipulations, for the proper performance of which special anatomical knowledge and manipulative skill are essential." If we are looking for it, surgical or anesthesiologic textbooks do not say more about this question today.

After the first definition, the greatest step was in this theme when the American Society of Anesthesiologists developed the ASA physical status classification system of the patients in 1940. Later, the score system was modified and broadened and before surgery patients' fitness can be classified into six categories [2, 3]. But surgical risk and stress should not be mistaken with the ASA score. The latter is shown in Table 1.

Generally, in elective operation the risk rises parallel to the extent of surgical area, if the length of surgery is longer than $2 \mathrm{~h}$, with the amount of intraoperative blood loss and with the decrease in body temperature that is measured during the operation. Moreover, surgical risk continues to increase much more if it is an acute intervention [4].

The development of a surgical system like to ASA began in Switzerland in 1992 [5]. In this paper, Clavien and co-workers proposed general principles to classify 
Table 1 Simplified version of ASA classification system

\begin{tabular}{ll}
\hline Grade & Physical status of the patient \\
\hline ASA1 & Healthy person \\
ASA2 & Mild systemic disease \\
ASA3 & Severe systemic disease \\
ASA4 & $\begin{array}{l}\text { Severe systemic disease that is a constant threat to life } \\
\text { ASA5 }\end{array}$ \\
& $\begin{array}{c}\text { A moribund person who is not expected to survive } \\
\text { without the operation }\end{array}$ \\
ASA6 & $\begin{array}{c}\text { A declared brain-dead person whose organs are being } \\
\text { removed for donor purposes }\end{array}$ \\
\end{tabular}

complications of surgery based on a therapy-oriented, four-level severity grading. Recently, this system contains three grades, where major and complex interventions mean same degree of severity $[6,7]$. Today, preoperative planning includes determination of severity degree, predictable blood loss and operative time associated with surgery. Postoperative outcome of the patient can be predicted with the knowledge of these risks (Table 2).

The timeliness of the question indicates a paper published in 2019 in The Lancet Commission on Global Surgery which identified that 313 million surgical procedures are performed worldwide each year. Startling data that number of postoperative deaths accounts for $7.7 \%$ of all deaths globally, making it on the "Top 10 global causes of death" list to the third (!) greatest contributor to deaths, after ischemic heart disease and stroke [8]. Besides this huge number, there is no doubt that we still know little about the surgical risk and surgical stress also. The stress itself and the consequences of them are known as a qualitative complex system. Changes in surgical stress can be measured under different surgical intervention as quantitative values would be useful information for everyday clinical practice.

From the 1960s, differential scanning calorimetry (DSC) is originally a well-known thermo-analytical method in the physical sciences. From the end of the twentieth century, DSC examination is a validly efficient method not only for the demonstration of structural changes, but also in numerous in vitro and in vivo biological systems [9-11]. Many researchers' works from the beginning of the twenty-first century revealed its potential for cancer disease diagnostics performed on human blood plasma [12-15].

These facts encouraged us to use DSC method in field of surgery also. The goal of this pilot study was to measure thermal changes of human blood plasma by DSC method on patients who underwent elective small or intermediate, or major surgical interventions. Moreover, beyond measurements received curves were unsealed and were deconvoluted to main plasma protein components as well.

\section{Materials and methods}

\section{Patient selection}

To this study, three different patient groups were established. Those who had pigmented nevi excision have joined to the minor surgical group $(n=8)$. They had low surgical risk; the operation time was under half an hour, while the predicted blood loss was under $200 \mathrm{~mL}$. Patients in intermediated operation group underwent lumpectomy due to benign breast lesions $(n=9)$. The pure surgical time in this medium risk patient group was under $1 \mathrm{~h}$, while blood loss was less than $1000 \mathrm{~mL}$. In contrast, major operative group $(n=7)$ contained that persons, who underwent pancreas surgical intervention after median laparotomy. Only that patients were selected to this group whose operative time (surgery without anesthesia) was longer than $2 \mathrm{~h}$, and during this high-risk surgical intervention their blood loss was more than $1000 \mathrm{~mL}$. In every group, the predicted and final blood loss was near the same, and under intervention patients did not receive any blood component transfusion. Each

Table 2 Classification of surgical grade and operative risk

\begin{tabular}{|c|c|c|c|c|c|}
\hline Surgery grade & Risk & $\begin{array}{l}\text { Predictable } \\
\text { blood loss } / \mathrm{mL}\end{array}$ & Extension of surgical area & Operative time/h & Examples \\
\hline Minor & Low & $<200$ & Small and superficial incision & $<0.5$ & $\begin{array}{l}\text { Excising skin lesion } \\
\text { Draining superficial abscess }\end{array}$ \\
\hline Intermediate & Medium & $<1000$ & $\begin{array}{l}\text { Depth of surgery does not exceed } \\
\text { superficial fascia }\end{array}$ & $<1$ & $\begin{array}{l}\text { Breast lumpectomy } \\
\text { Inguinal hernia repair } \\
\text { Hemorrhoidectomy } \\
\text { Tonsillectomy }\end{array}$ \\
\hline Major or complex & High & $>1000$ & Opening body cavities, organ surgery & $>2$ & $\begin{array}{l}\text { Opening of one or more body } \\
\text { cavities (abdomen, thorax, } \\
\text { skull) } \\
\text { Organ resections } \\
\text { Organ transplantation }\end{array}$ \\
\hline
\end{tabular}


operation was performed in the Surgical Clinic of Pécs University, Hungary. The protocols were approved by regional ethical committee of the University (27.06.2008/3220; 360.316-12736/2009).

\section{Blood sample collection and preparation}

Peripheral blood samples were collected from patients $(n=24)$ after their surgical treatments, and from healthy controls ranging from 22 to 62 years old $(n=5)$. Blood samples were collected into the Vacutainer tubes containing EDTA (1.5 mg mL $\mathrm{mL}^{-1}$ of blood) centrifuged at $1.600 \mathrm{~g}$ for $15 \mathrm{~min}$ at $4{ }^{\circ} \mathrm{C}$ to separate plasma fraction from cell components. Native plasmas were stored at $-80{ }^{\circ} \mathrm{C}$ until DSC measurement.

\section{Calorimetric measurement}

The thermal unfolding of the human plasma components was monitored by SETARAM Micro DSC-II calorimeter as previously described [16]. Briefly, all experiments were conducted between 0 and $100{ }^{\circ} \mathrm{C}$. The heating rate was $0.3 \mathrm{~K} \mathrm{~min}^{-1}$ in all cases. Conventional Hastelloy batch vessels were used during the denaturation experiments with $850 \mu \mathrm{L}$ sample volume in average. Reference sample was normal saline $(0.9 \% \mathrm{NaCl})$. The sample and reference samples were equilibrated with a precision of $\pm 0.1 \mathrm{mg}$. The repeated scan of denatured sample was used as baseline reference, which was subtracted from the original DSC curve. We have plotted the $C_{\mathrm{P}}$ heat flow (DSC-II is a heat flux instrument with hermetically closed vessels) in the function of temperature. Calorimetric enthalpy was calculated from the area under the heat flow curve by using two-point setting SETARAM peak integration.

\section{Deconvolution of DSC thermal curve}

Blood plasma is a complex protein mixture. Therefore, it contains from thermal point of view different "thermal domains" which can be assigned to the different compounds [17-19]. It means that a DSC scan can be decomposed into a sum of Gaussian curves such that their total area is the same as that of the experimental curve, within a reasonable error $(<1 \%)$. To have the best fitting, we applied more than five curves, but some contribution was less than the error of enthalpy determination, so they cannot influence our final interpretation of data.

\section{Statistical analysis}

All results are given in mean values \pm standard error of the mean (SEM). Data were analyzed with one-way ANOVA. The level of significance was set at $p<0.05$.

\section{Results}

Previous recorded DSC plasma profile from healthy individuals contained 5 well-resolved transitions at about $56{ }^{\circ} \mathrm{C}, 62{ }^{\circ} \mathrm{C}, 65{ }^{\circ} \mathrm{C}, 74{ }^{\circ} \mathrm{C}$ and $82{ }^{\circ} \mathrm{C}(17-19) . T_{\mathrm{m} 1}$ transition can be attributed mainly to fibrinogen, $T_{\mathrm{m} 2}$ to albumin, $T_{\mathrm{m} 3}$ to immunoglobulins and albumin minor tail, $T_{\mathrm{m} 4}$ to complement protein C3, IgA, IgG, and finally $T_{\mathrm{m} 5}$ to one part of $\operatorname{IgG}$ and transferrin. Although the DSC data from our study reveal heterogeneity in the curves, some common characteristics for the majority after surgery plasma profiles were observable. Generally, after any surgical intervention patients' blood plasma curves were shifted more or less toward lower denaturation temperatures compared to healthy controls. Figure $1 \mathrm{a}-\mathrm{c}$ shows measured calorimetric changes of blood plasma proteins as a cumulated curves (black lines, experimental). Thereafter measured main thermal curve (black line) deconvoluted usually was unfolded to 5-8 melting components (colored lines). The order of appearance of each component in case of five transition temperatures was green, blue, pink, dark yellow, and purple. The order in case of eight $T_{\mathrm{m}} \mathrm{s}$ was the follows: green, blue, pink, dark yellow, navy, purple, brown, and dark cyan.

Following minor surgery, the first transition temperature (fibrinogen) from deconvoluted patients curves remained on the healthy controls' temperature $\left(56^{\circ} \mathrm{C}\right)$ value. While the second transition giving albumin's melting point showed mild decrease, the third immunoglobulins melting temperature decreased from 65.3 to $64.1^{\circ} \mathrm{C}$. The decrease was more significant for $T_{\mathrm{m} 4}$, but $T_{\mathrm{m} 5}$ slightly increased (Fig. 1a; Table 3). After intermediate surgical intervention, blood plasma melting temperatures showed a downward trend compared to both samples from healthy volunteers, and from patients after minor surgery. There was only one exception, $T_{\mathrm{m} 3}$, where transition temperature showed mild increase. The most dominant changes occurred in plasma after major surgery. Surprisingly, during deconvolution of blood plasma cumulative DSC curve was separable to eight well-separated melting components. Accordingly, $T_{\mathrm{m} 1}$ was lower than ever before; this decrease was more than $10{ }^{\circ} \mathrm{C}\left(45^{\circ} \mathrm{C}\right.$ vs. $\left.56{ }^{\circ} \mathrm{C}\right)$. The $T_{\mathrm{m} 7}$ was near to the healthy $T_{\mathrm{m} 4}$, while $T_{\mathrm{m} 8}$ was near to control $T_{\mathrm{m} 5}$ values. According to temperature range, the given melting temperatures between $T_{\mathrm{m} 2}$ and $T_{\mathrm{m} 6}$ were near similar which are in healthy $T_{\mathrm{m} 2}$ and $T_{\mathrm{m} 3}$.

The calorimetric enthalpy, as an indicator of overall thermal stability of the whole system, showed a mild decrease after minor surgery compared to control $\left(1.29 \mathrm{~J} \mathrm{~g}^{-1} \mathrm{vs}\right.$. $0.94 \mathrm{~J} \mathrm{~g}^{-1}$ ). According to our measurements, the enthalpy changed parallel and in proportional manner to the size of surgical intervention $\left(1.11 \mathrm{~J} \mathrm{~g}^{-1} ; 1.45 \mathrm{~J} \mathrm{~g}^{-1}\right)$. 

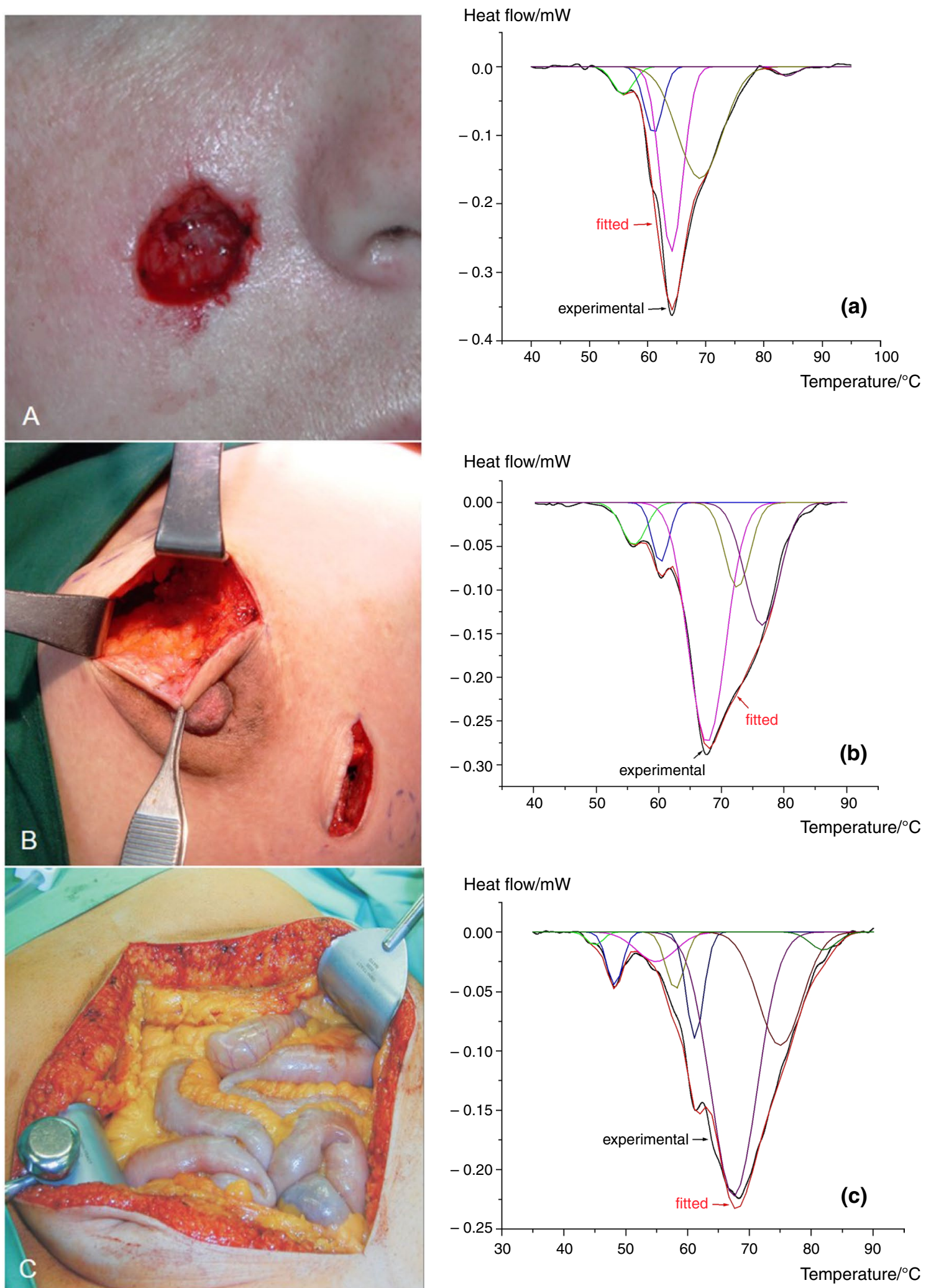

Fig. 1 Intraoperative pictures represent fusiform excision as a minor surgery (A), lumpectomy as an intermediate operation (B), and median laparotomy as a major surgical intervention (C). Belongs to

these operations deconvoluted DSC thermal curves of blood plasma components are at their right side $(\mathbf{a}-\mathbf{c})$ 
Table 3 Melting temperatures and calorimetric enthalpies of human blood plasma in healthy individuals, and in patients who underwent minor or intermediate, or major surgical interventions (transition tem-

\begin{tabular}{|c|c|c|c|c|c|c|c|c|c|}
\hline \multirow[t]{2}{*}{ Human blood plasma samples } & \multicolumn{8}{|l|}{$T_{\mathrm{m}} /{ }^{\circ} \mathrm{C}$} & \multirow[t]{2}{*}{$\Delta H / \mathrm{J} \mathrm{g}^{-1}$} \\
\hline & $T_{\mathrm{m} 1}$ & $T_{\mathrm{m} 2}$ & $T_{\mathrm{m} 3}$ & $T_{\mathrm{m} 4}$ & $T_{\mathrm{m} 5}$ & $T_{\mathrm{m} 6}$ & $T_{\mathrm{m} 7}$ & $T_{\mathrm{m} 8}$ & \\
\hline Healthy controls $(n=5)$ & $56 \pm 0.04$ & $62.5 \pm 0.39$ & $65.3 \pm 0.7$ & $74.8 \pm 0.17$ & $82 \pm 0.02$ & - & - & - & $1.29 \pm 0.06$ \\
\hline Minor surgery $(n=8)$ & $55.8 \pm 0.2$ & $61 \pm 0.2$ & $64.1 \pm 0.2$ & $69 \pm 0.2$ & $84 \pm 0.3$ & & - & - & $0.94 \pm 0.08$ \\
\hline Intermediate surgery $(n=9)$ & $56 \pm 0.2$ & $60.25 \pm 0.2$ & $67.7 \pm 0.3$ & $72.55 \pm 0.3$ & $76.5 \pm 0.1$ & & - & - & $1.11 \pm 0.06$ \\
\hline Major surgery $(n=7)$ & $45 \pm 0.2$ & $48.2 \pm 0.2$ & $54.9 \pm 0.2$ & $58 \pm 0.1$ & $61.2 \pm 0.04$ & $67.5 \pm 0.2$ & $75 \pm 0.2$ & $82 \pm 0.1$ & $1.45 \pm 0.07$ \\
\hline
\end{tabular}

perature: $T_{\mathrm{m}} /{ }^{\circ} \mathrm{C}$; calorimetric enthalpy: $\Delta H / \mathrm{J} \mathrm{g}^{-1}$; average $\pm \mathrm{SD}$ for $n>5$, except of $\Delta H$, rounded to one places of decimals)

\section{Discussion}

These results can be considered as novel because no other results describing blood plasma such changes with thermo-analytical method on patients who underwent different sizes of surgery. Several research groups have investigated blood plasma changes in patients who treated for cancer, inflammatory disease or other causes. But this is the first research that shows the extent of surgical invasiveness alone influences the change in plasma composition. Having regard to the lack of comparable articles, we assume that there are three reasons for the explanation of change. First, with an increase in surgical time patient gets more intravenous infusions, which means extra fluid administration will dilute blood plasma protein components. There may be visible a "purifier" picture of diluted plasma proteins, including any small proteins or peptides also. According to our hypothesis transition temperatures change not only numerically. There is no doubt that qualitative changes may also be responsible for the dramatic changes in melting temperatures after $2 \mathrm{~h}$ surgery. Other researchers explained these results with conformational changes or protein modifications during their calorimetric denaturation [20]. Third possible explanation is that specific interactions should be between small and most abundant proteins or other circulating molecules which are present in different diseases [21]. The obtained results suggest that mapping of human plasma proteins by DSC method and they introduce should be a possible novel and non-invasive diagnostic tool. Nevertheless, further studies are needed to prove our assumptions and for a reassuring interpretation of given results.

Despite the fact that the development of surgery has been going on for thousands of years, and modern surgery is more than 170 years old, it is still a question of what size of stress a patient has on surgery. In many cases, university textbooks or conventional blood tests do not give an exact answer. This article highlighted the significant difference in categorization of surgical procedures. The results obtained are extremely different, but this paper focused on the problem and on the changes causing surgical intervention which 
10. Schäffer B, Lőrinczy D, Szakály S. DSC and EPR investigation of the effect of fat crystallization on the consistency of butter. $\mathrm{J}$ Therm Anal. 1996;47:515-24.

11. Ferencz A, Nedvig K, Lőrinczy D. DSC examination of the intestinal tissue following ischemic injuries. In: Lőrinczy D, editor. Thermal analysis in medical application. Budapest: Akadémiai Kiadó; 2011. p. 255-69.

12. Garbett NC, Mekmaysy CS, DeLeeuw L, Chaires JB. Clinical application of plasma thermograms. Utility, practical approaches and considerations. Methods. 2015;76:41-50.

13. Ferencz A, Fekecs T, Lőrinczy D. Differential scanning calorimetry as a new method to monitor human plasma in melanoma patients with regional limph node or distal metastases. In: Yaguang X, editor. Skin cancer book. Rijeka: InTech; 2011. p. 141-53.

14. Medhi M, Zapf I, Fekecs T, Nedvig K, Lőrinczy D, Ferencz A. Influence of oxidative injury and monitoring of blood plasma by DSC on patients with psoriasis. J Therm Anal Calorim. 2016;123:2037-43.

15. Búcs G, Nőt LG, Dandé Á, Wiegand N, Lőrinczy D. Detection of joint capsule changes by differential scanning calorimetry (DSC) in different types of hip disorders to evaluate surgical techniques (a preliminary report). J Therm Anal Calorim. 2017;130:1293-6.

16. Ferencz A, Lőrinczy D. DSC measurements of blood plasma on patients with chronic pancreatitis and operable and inoperable pancreatic adenocarcinoma. J Therm Anal Calorim. 2017;127:1187-92.

17. Garbett NC, Mekmaysy C, Helm CV, Jenson AB, Chaires JB. Differential scanning calorimetry of blood plasma for clinical diagnosis and monitoring. Exp Mol Pathol. 2009;86:186-91.

18. Todinova S, Krumova S, Kurtev P, Dimitrov V, Djongov L, Dudunkov Z, Taneva SG. Calorimetry-based profiling of blood plasma from colorectal cancer patients. Biochim Biophys Acta. 2012;1820:1879-85.

19. Michnik A, Drzazga Z. Thermal denaturation of mixtures of human serum proteins: DSC study. J Therm Anal Calorim. 2010;101:513-8.

20. Garbett NC, Miller JJ, Jenson AB, Miller DM, Chaires JB. Interrogation of the plasma proteome with differential scanning calorimetry. Clin Chem. 2007;53:2012-4.

21. Zhou M, Lucas DA, Chan KC, Issaq HJ, Petricoin EF, Liotta LA, Veenstra TD, Conrads TP. An investigation into the human serum "interactome". Electrophoresis. 2004;25:1289-98.

Publisher's Note Springer Nature remains neutral with regard to jurisdictional claims in published maps and institutional affiliations. 